\title{
EFEITO IN VITRO DO ÓLEO ESSENCIAL E EXTRATO AQUOSO DE OCIMUM GRATISSIMUM COLHIDO NAS QUATRO ESTAÇÕES DO ANO SOBRE FITOPATÓGENOS
}

\author{
P.C. Benini ${ }^{1}$, K.R.F. Schwan-Estrada ${ }^{1 *}$, E.C. Klais ${ }^{1}$, M.E.S. Cruz ${ }^{1}$, \\ A.T. Itako ${ }^{1}$, R.M. Mesquini' ${ }^{1}$, J.R. Stangarlinn ${ }^{2 *}$, J.B. Tolentino Júnior ${ }^{1}$
}

${ }^{1}$ Universidade Estadual de Maringá, Departamento de Agronomia, Av. Colombo, 5.790, CEP 87020-900, Maringá, PR, Brasil. E-mail: schwan@wnet.com.br

\section{RESUMO}

\begin{abstract}
O trabalho foi desenvolvido para verificar o efeito do óleo essencial e do extrato bruto de alfavaca-cravo (Ocimum gratissimum), coletado nas quatro estações do ano, no crescimento micelial in vitro dos fungos Rhizoctonia solani, Sclerotium rolfsii, Phytophthora sp. e Alternaria alternata. Para avaliar o efeito do óleo essencial no crescimento micelial dos fungos, alíquotas de $20 \mu \mathrm{L}, 40 \mu \mathrm{L}$ e $60 \mu \mathrm{L}$ de óleo esterilizado foram distribuídas na superfície de meio BDA (batata-dextrose-ágar) antes da repicagem dos fungos. O extrato bruto aquoso (EBA) foi filtrado e incorporado em BDA nas concentrações de 1\%, 5\%, 10\%, 15\%, 20\%, 25\% e $50 \%$. Os resultados indicaram que houve inibição total do crescimento micelial dos fungos nas diferentes alíquotas de óleo essencial. O EBA das plantas colhidas no outono proporcionou os melhores resultados, sendo que nesta estação do ano o EBA na concentração de 5\% foi suficiente para promover $100 \%$ de inibição do crescimento micelial dos fitopatógenos A. alternata e $S$. rolfsii.
\end{abstract}

PALAVRAS-CHAVE: Alfavaca cravo, controle alternativo, planta medicinal.

\section{ABSTRACT}

IN VITRO EFFECT ON PHYTOPATHOGENS OF ESSENTIAL OIL AND AQUEOUS CRUDE EXTRACT OF OCIMUM GRATISSIMUM HARVESTED IN THE FOUR SEASONS. The present work aimed to evaluate the effects of the essential oil and crude extract of wild basil (Ocimum gratissimum), harvested in different seasons, on the in vitro mycelia growth of Rhizoctonia solani, Sclerotium rolfsii, Phytophthora sp. and Alternaria alternata. To evaluate the effect of the essential oil, sterilized oil aliquots of $20 \mu \mathrm{L}, 40 \mu \mathrm{L}$ and $60 \mu \mathrm{L}$ were distributed on the surface of potato-dextroseagar (PDA). The aqueous crude extracts (ACE) were filtrated and incorporated in PDA at 1\%, 5\%, $10 \%, 15 \%, 20 \%, 25 \%$ and $50 \%$. The results showed total inhibition of mycelial growth in the different aliquots of essential oil. The ACE collected from plants in autumn had better results; in this season the ACE at $5 \%$ was enough to provide $100 \%$ of mycelia growth inhibition of A. alternata and S. rolfsii.

KEY WORDS: Wild basil, alternative control, medicinal plants.

\section{INTRODUÇÃO}

Ocimum gratissimum (alfavaca-cravo) éuma planta considerada medicinal, pois em sua composição química, encontram-se substancias ativas, biologicamente sintetizadas. Estas substâncias podem ser utilizadas direta ou indiretamente como medicamentos, pois provocam, no organismo humano, reações como a cura ou abrandamento de doenças (CASTRO; FERREIRA, 2000; CASTRO et al., 2004). Esta planta possui óleo essencial rico em eugenol (40-66\%) e timol (31\%) (VIEIRA; SimON, 2000) com ação antisséptica local contra fungos (ação fungicida) e bactérias (ação bactericida) e apresenta seu maior teor entre 11 e 13 horas, período que é recomendável para colheita (MATOS, 1997; MARTins et al., 2000).

As etapas de colheita e pós-colheita de plantas medicinais são importantes para a obtenção de maior quantidade e qualidade dos óleos essenciais. Entre os principais fatores que se deve levar em consideração na colheita estão a época e horário da colheita, a temperatura e o tempo de secagem (CARVALHO FiLHo et al., 2006; MARTINs et al., 2000; CASTRO et al., 2004). O conhecimento dos fatores que influenciam a variação dos compostos químicos nas plantas medicinais auxilia na obtenção de matéria-prima de qualidade e, consequentemente, de produto final de boa qualidade (CASTRO et al., 2004).

${ }^{2}$ Universidade Estadual do Oeste do Paraná, Marechal Cândido Rondon, PR, Brasil.

*Bolsista Produtividade CNPq. 
SiLva et al. (1995) citaram que algumas substâncias, como o eugenol, cineol, metil chavicol e linalol, sintetizadas pelas plantas medicinais, são utilizadas em seres humanos por possuírem propriedades antimicrobianas. Estes mesmos compostos secundários podem exercer na planta diversas funções importantes, como nas interações planta-planta (alelopatia), planta-animal (anti-herbivoria, atração de agentes polinizadores) e planta-micro-organismo patogênico. Nesta última função, tais compostos podem participar das respostas de defesa da planta em um sistema natural, quer seja na planta que os produz ou em outras interações planta-patógeno, atuando como substâncias fungitóxicas à semelhança dos fungicidas sintéticos. Também podem atuar como antissépticos em seres humanos.

A atividade antimicrobiana de plantas medicinais utilizando-as como extratos e óleos essenciais tem sido frequentemente citada na literatura, tanto em experimentosinvitro quanto in vivo. Como exemplos, podem ser mencionados os trabalhos deSTANGARLINet al. (1999) com extrato bruto aquoso (EBA) de arruda e manjericão na inibição de Sclerotium rolfsii; FIORI et al. (2000) com Eucalyptus citriodora, Cymbopogon citratus, Ageratum conyzoides e Achillea millefolium na inibição do crescimento micelial, esporulação e germinação de Didymella bryoniae; ROzWALKA (2003) com o EBA de Rosmarinus officinalis observaram redução de $67 \%$ e $47,49 \%$ no crescimento micelial dos fungos Glomerella cingulata e de Colletotrichum gloeosporioides, respectivamente e, BALBI-PEÑA et al. (2006), com extrato de cúrcuma (Curcuma longa) na inibição de Alternaria solani, observaram que extratos aquosos não autoclavados, nas concentrações de 10 e $15 \%$, inibiram o crescimento micelial em $38,2 \%$ e $23,2 \%$, respectivamente.

Assim, o presente trabalho teve como objetivo avaliar os efeitos do óleo essencial e extrato bruto aquoso de Ocimum gratissimum (alfavaca-cravo), colhido nas quatro estações do ano, no crescimento micelial in vitro dos fungos Rhizoctonia solani, Sclerotium rolfsii, Phytophthora sp. e Alternaria alternata.

\section{MATERIAL E MÉTODOS}

As plantas de $O$. gratissimum utilizadas nos experimentos foram obtidas no Horto de Plantas Medicinais do Departamento de Agronomia da Universidade Estadual de Maringá (UEM) e colhidas entre os horários de $12 \mathrm{~h}$ e $14 \mathrm{~h}$ nos meses de janeiro, abril, julho e outubro, representando cada estação do ano. Os experimentos foram realizados nos laboratórios de Plantas Medicinais e de Fitopatologia da UEM.

\section{Obtenção dos isolados}

Os isolados de Rhizoctonia solani, Sclerotium rolfsii, Phytophthora sp. e Alternaria alternata foram cedidos pela micoteca do Laboratório de Fisiologia do Parasitismo da ESALQ/USP. Os fungos foram repicados e mantidos em meio de cultura BDA (batata-dextrose-ágar) à temperatura de $24 \pm 2^{\circ} \mathrm{C} \mathrm{e}$ fotoperíodo de $12 \mathrm{~h}$.

\section{Obtenção doóleo essencial e extrato bruto aquoso}

Oóleo essencial foi obtido pelo método de arraste a vapor (COSTA, 1986), tendo sido utilizados de 500 a $1.000 \mathrm{~g}$ de folhas frescas e picadas, colhidas durante o ano, nas quatro estações.

Para obtenção do extrato bruto aquoso, folhas frescas nas quantidades de 10, 50, 100, 150, 200, 250 e $500 \mathrm{~g}$ foram coletadas nas quatro estações do ano e trituradas em $1 \mathrm{~L}$ de água destilada por $1 \mathrm{~min}$, em liquidificador. Os homogenatos resultantes foram filtrados em gaze e em papel de filtro Whatman no 1 , obtendo-se o extrato bruto aquoso, o qual foi utilizado no mesmo dia do preparo.

Efeito in vitro do óleo essencial e do extrato bruto aquoso de $O$. gratissimum no crescimento micelial dos fungos fitopatogênicos

Após esterilização por filtração em membrana Millipore, alíquotas de 20,40 e $60 \mu \mathrm{L}$ do óleo essencial foram depositadas no centro de placas de Petri contendo meio BDA e distribuídas na superfície do meio com alça de Drigalsky. A seguir, um disco de micélio $(8 \mathrm{~mm}$ de diâmetro) dos isolados de $R$. solani, $S$. rolfsii, Phytophthora sp. e A. alternata, retirados de colônias com 10 dias de idade em BDA, foi repicado para o centro de cada placa que foram vedadas com filme plástico e mantidas a $28^{\circ} \mathrm{C}$ $\pm 2^{\circ} \mathrm{C}$, no escuro. Como testemunha foi utilizada água destilada esterilizada.

Folhas frescas de alfavaca-cravo, colhidas nas quatro estações do ano, foram trituradas em água destilada por $1 \mathrm{~min}$ em liquidificador e os homogenatos resultantes foram submetidos à filtragem em gaze e em papel de filtro Whatman no1, obtendo-se EBA. A seguir, o EBA foi incorporado ao meio BDA de modo a obterem-se concentrações de $1,5,10,15,20,25$ e $50 \%$, sendo então autoclavados $\left(121^{\circ} \mathrm{C} / 20 \mathrm{~min}\right)$ e distribuídos em placas de Petri. Após a solidificação do meio, disco de micélio (8 $\mathrm{mm}$ de diâmetro) com 10 dias de idade de cada um dos isolados foram repicados para o centro de cada placa e estas, em seguida, foram vedadas com filme plástico e incubadas a $28^{\circ} \mathrm{C} \pm 2^{\circ} \mathrm{C}$ em escuro. $\mathrm{O}$ tratamento testemunha consistiu de placas com apenas BDA.

O crescimento micelial foi avaliado através da mensuração diária do diâmetro das colônias no sentido diametralmente oposto do crescimento. O período da avaliação 
foi o compreendido entre 24 horas após a instalação do experimento até o momento em que as colônias fúngicas do tratamento testemunha, de cada um dos fitopatógenos, apresentaram crescimento em $2 / 3$ da superfície do meio de cultura. $\mathrm{O}$ delineamento experimental foi inteiramente casualizado (DIC) com cinco repetições, em esquema fatorial $8 \times 4+1$ e $4 \times 4+1$ para o EBA e OE, respectivamente, cujos fatores foram concentrações, isolados fúngicos e testemunha. Os dados obtidos foram submetidos à análise de variância $(p=0,05)$ e, quando significativos, foram analisados por regressão, correlacionando porcentagem de inibição de crescimento micelial (ICM) e concentração de EBA e OE para cada fungo. Para a análise dos dados de crescimento micelial com EBA, foram ajustados os modelos quadráticos $\left(\mathrm{y}=\mathrm{yo}+\mathrm{ax}+\mathrm{bx}^{2}\right)$ e inversa de primeira ordem $\left(y=y_{0}+a / x\right)$. As análises de regressão foram realizadas por meio do programa SAS 9.1 (SAS Institute, 2002).

Para o cálculo dos porcentuais de inibição do crescimento micelial (ICM) em meio de cultivo, tanto para o óleo essencial (OE) como para o extrato bruto aquoso (EBA), utilizou-se à fórmula (BASTOS, 1997):

ICM $=\underline{\text { Cresc. } . \text { Testemunha }- \text { Cresc. Tratamento }} \times 100$ Cresc. Testemunha

\section{RESULTADOS E DISCUSSÃO}

Observando os resultados do óleo essencial sobre o crescimento micelial (Fig. 1), verificou-se que todas as alíquotas do $\mathrm{OE}$ de $O$. gratissimum inibiram totalmente o crescimento micelial dos fungos $R$. solani, $S$. rolfsii, Phytophthora sp. e A. alternata. STANGARLin et al. (1999) observaram $100 \%$ de inibição na germinação de conídios de Colletotrichum graminicola quando na presença de $\mathrm{OE}$ de $O$. gratissimum. FARIA et al. (2006) verificaram que o óleo essencial de $O$. gratissimum inibiu o crescimento de Botryosphaeria rhodina, duas espécies de Alternaria sp. e Penicillium chrysogenum e associaram esta atividade antifúngica ao eugenol. FeNG; ZHENG (2007), trabalhando com óleo essencial de tomilho e cássia, em diferentes concentrações (100 a 500 ppm), observaram $100 \%$ de inibição do crescimento micelial de A. alternata quando na presença de 300 ppm de óleo de cássia e/ou tomilho.

Com relação aos extratos aquosos, pode-se verificar que os extratos oriundos das plantas colhidas no outono, na concentração a partir de 5\%, inibiiram totalmente o crescimento micelial R. solani (Fig. 2). OEBAde plantas colhidas no verão proporcionou inibição total do crescimento, nas concentrações acima de $10 \%$, enquanto o EBA oriundo de plantas coletadas no inverno ena primavera proporcionou $100 \%$ de inibição do crescimento micelial a partir da concentração de $15 \%$. Para o desenvolvimento de Phytophthora sp. (Fig. 3), observa-se que concentrações de EBA acima de 5\% proporcionaram inibição total do crescimento micelial, quando provieram de plantas colhidas no outono. O EBA de plantas colhidas no inverno, na primavera e verão provocaram inibição do crescimento micelial deste fitopatógeno, nas concentrações a partir de $10 \%$. Vários outros trabalhos relatam o efeito desta espécie de planta ou mesmo deste gênero em outros fitopatógenos, tais como os resultados obtidos por $\mathrm{AwAH}$ (1989) onde verificou que o EBA de $O$. gratissimum inibiu o crescimento micelial de Ustilago maydis, Ustilaginoidea virens, Curvularia lunata e Rhizopus sp. nas concentrações de 10 a $60 \%$, além de reduzir $75 \%$ o desenvolvimento das lesões causadas por Phytophthora palmivora em fruto de cacau inoculado com o fungo e tratado com extrato foliar. Este autor verificou também potencial erradicante sobre os esporângios desse fungo (AwAH, 1994).

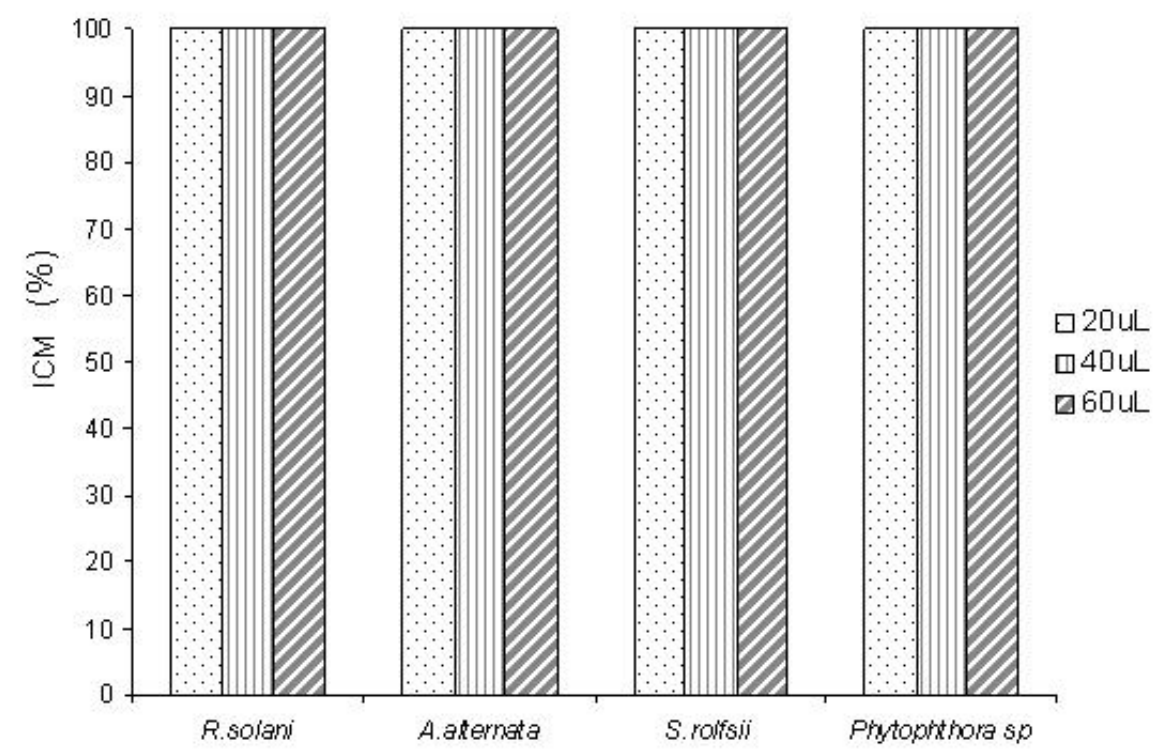

Fig. 1 - Inibição in vitro do crescimento micelial (ICM \%) de fungos fitopatogênicos em presença de óleo essencial de Ocimum gratissimum. 

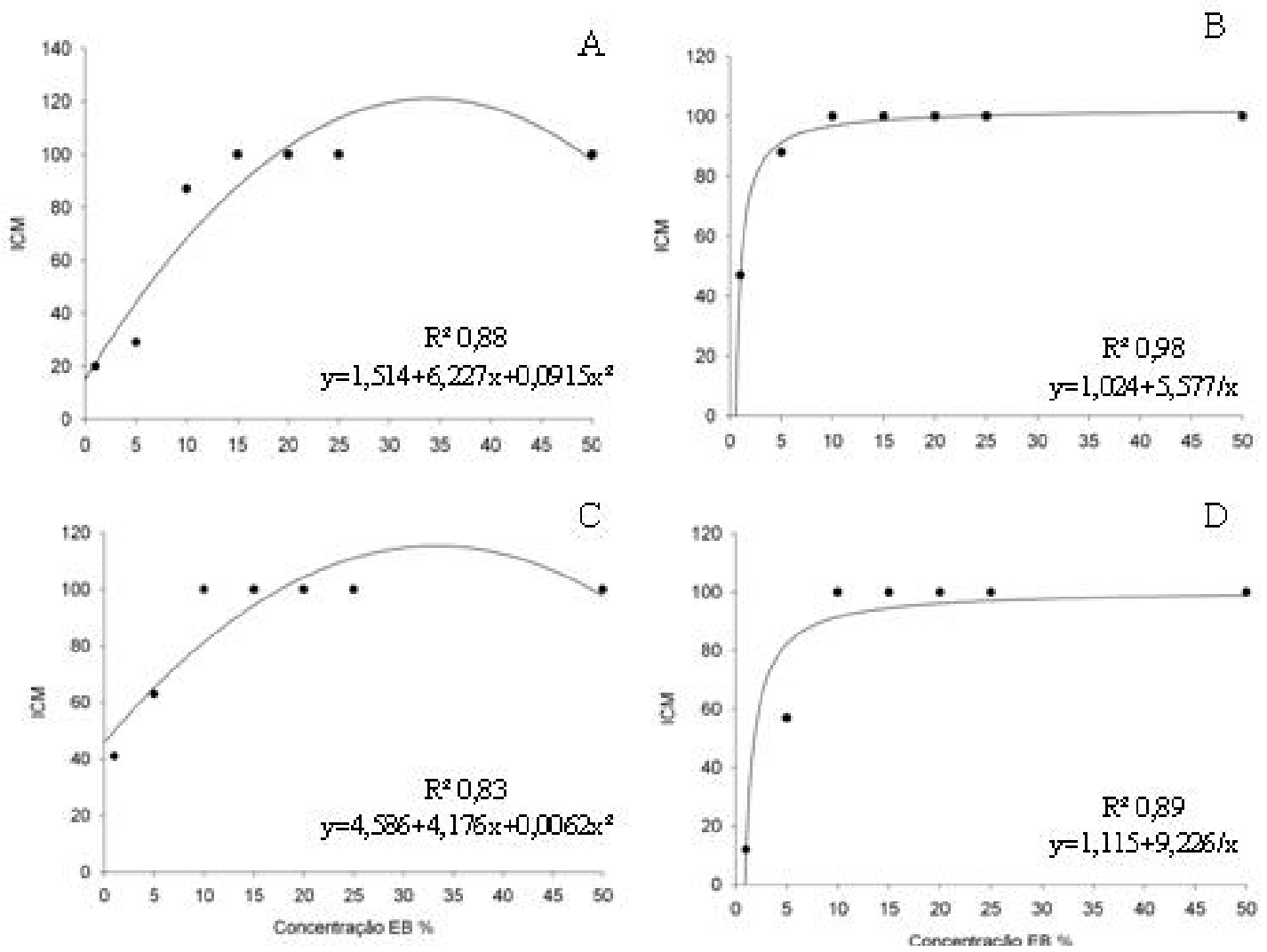

Fig. 2 - Inibição in vitro do crescimento micelial (ICM \%) de Rhizoctonia solani, em presença de extrato bruto da planta Ocimum gratissimum, coletada nas quatro estações do ano. A: Inverno; B: outono; C: primavera; D: verão.
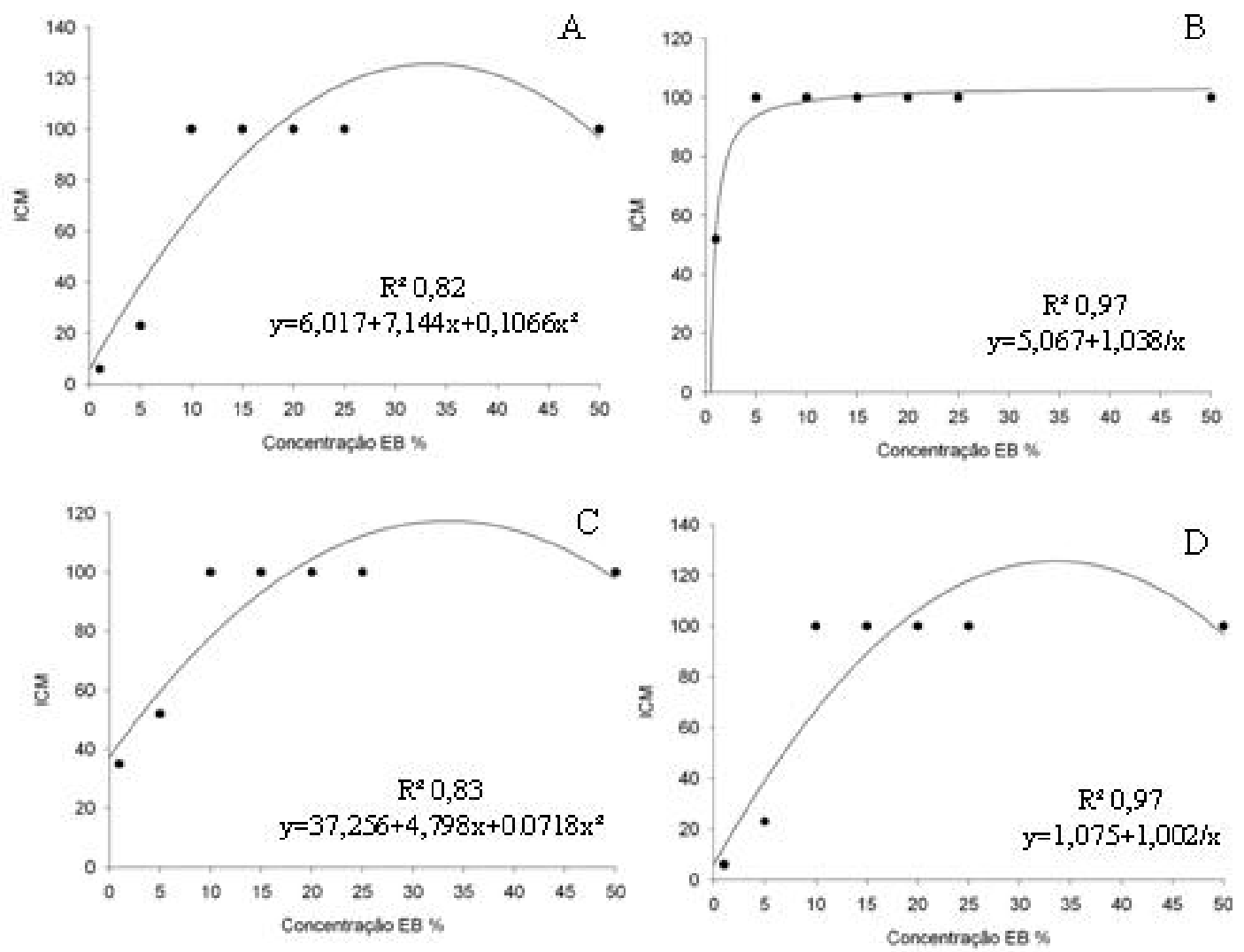

Fig. 3 - Inibição in vitro do crescimento micelial (ICM \%) de Phytophthora sp, em presença de extrato bruto da planta Ocimum gratissimum, coletada nas quatro estações do ano. A: Inverno; B: outono; C: primavera; D: verão. 

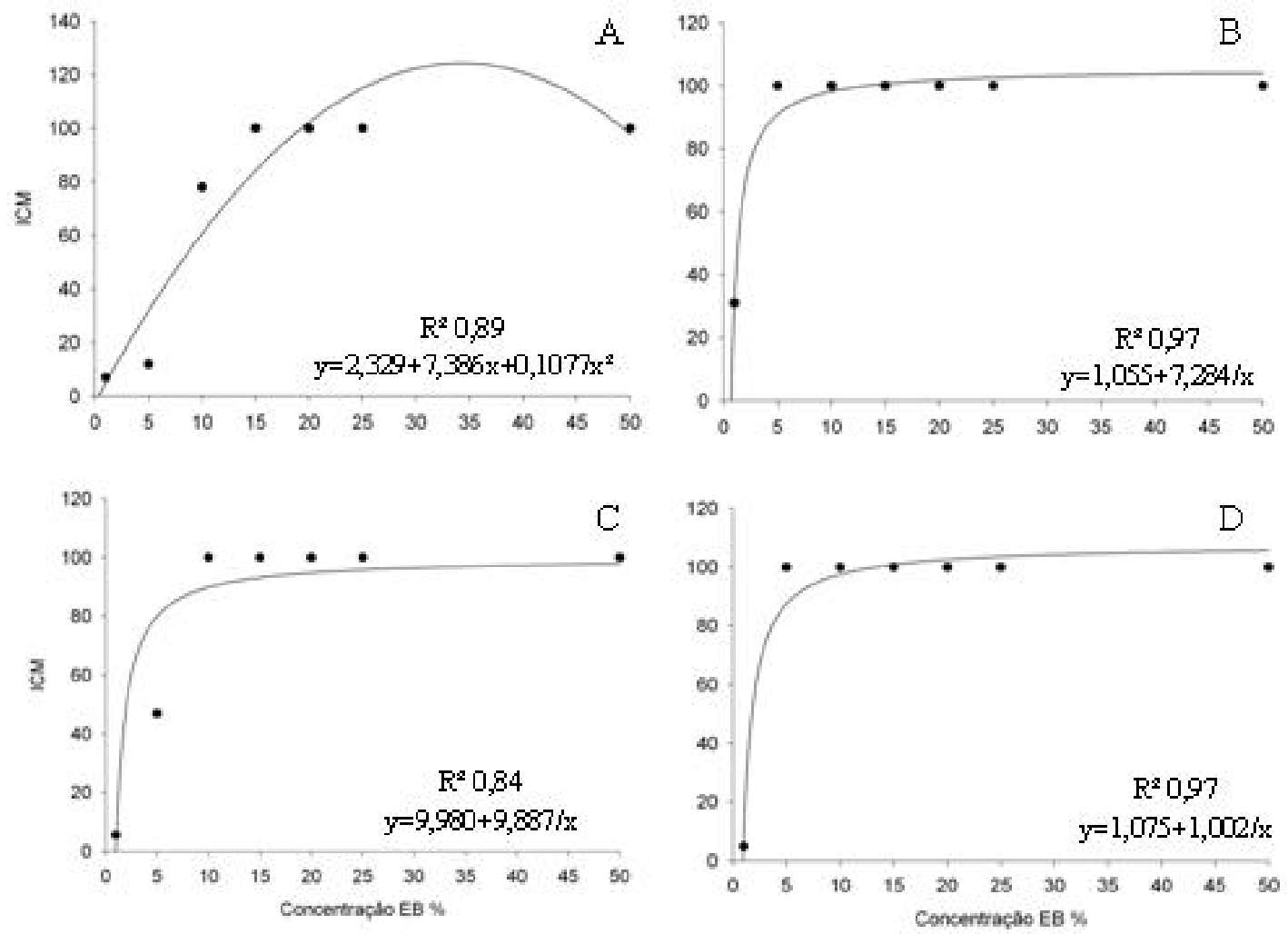

Fig. 4 - Inibição in vitro do crescimento micelial (ICM \%) de Sclerotium rolfsii, em presença de extrato bruto da planta Ocimum gratissimum, coletada nas quatro estações do ano. A: Inverno; B: outono; C: primavera; D: verão.
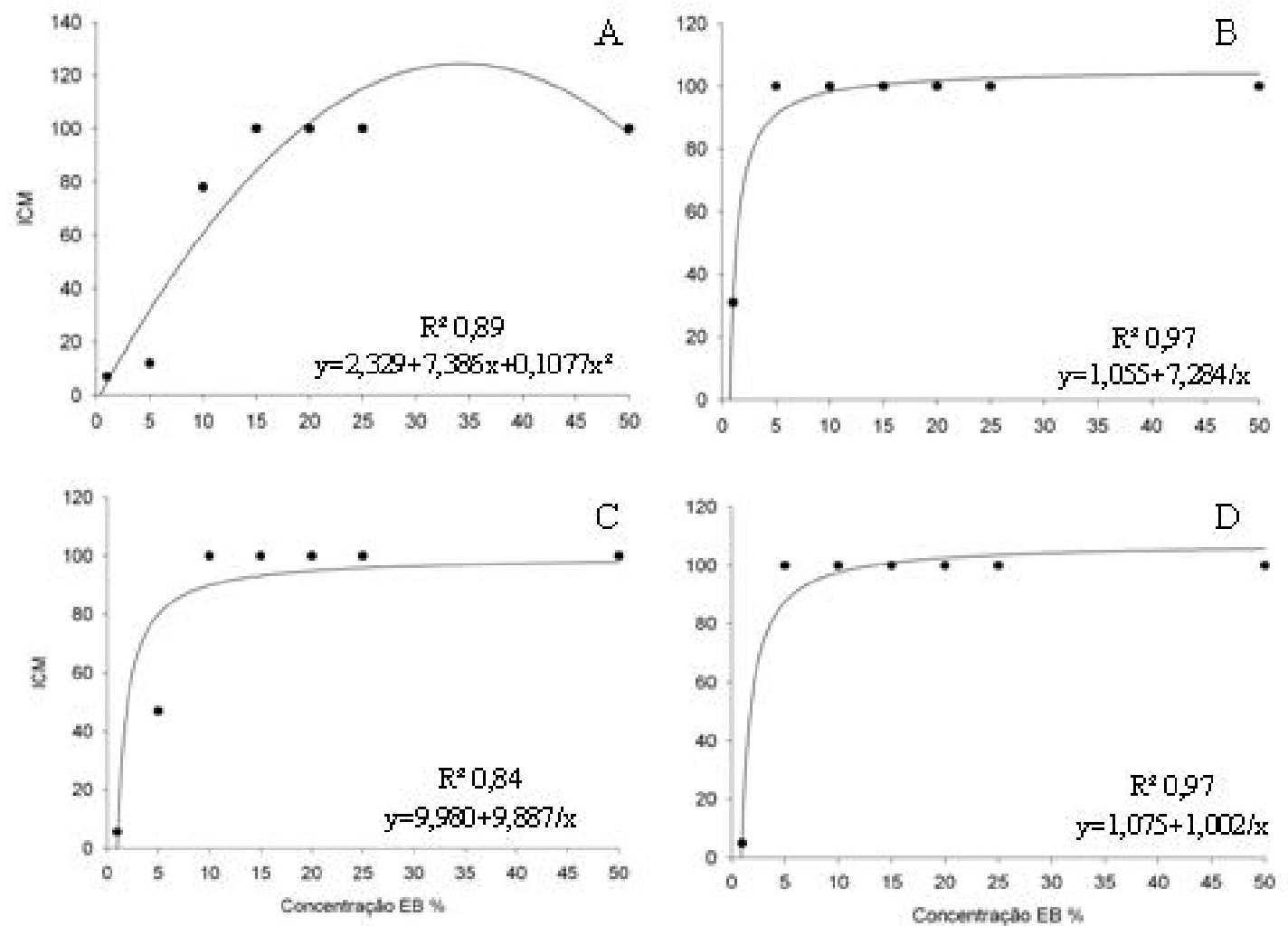

Fig. 5 - Inibição in vitro do crescimento micelial (ICM \%) de Alternaria alternata, em presença de extrato bruto da planta Ocimum gratissimum, coletada nas quatro estações do ano. A: Inverno; B: outono; C: primavera; D: verão. 
Para S. rolfsii (Fig. 4), pode-se observar pela análise de regressão queEBA de plantas colhidas no inverno promoveram inibição total do crescimento micelial, a partir de 15\%, enquanto EBA de plantas colhidas nas demais estações do ano proporcionaram inibição total do crescimento micelial deste fitopatógeno, em concentrações iguais ou acima de $10 \%$. Para $A$. alternata (Fig. 5), observou-se $100 \%$ de inibição deste fitopatógeno a partir da concentração de $5 \%$ do EBA das plantas colhidas nas estações do outono e verão. Extratos brutos aquosos de plantas colhidas no inverno e na primavera promoveram inibição a partir de $15 \%$ e $10 \%$, respectivamente.

Ensaios realizados por Rosset et al. (2005) para verificar a atividade antifúngica do extrato etanólico de $O$. gratissimum, utilizando a técnica de difusão em meio sólido, evidenciaram a inibição do crescimento de Penicillium chrysogenum, Rhizoctonia sp., Aspergillus niger e de duas espécies de Alternaria sp. isoladas de tomate e de cenoura. Estes autores também concluíram que o eugenol foi um dos prováveis compostos responsáveis pela atividade antifúngica do extrato, ratificando os registros da literatura que comprovam a atividade deste constituinte contra várias espécies de fungos (DuBEY et al., 2000; NAKAMURA et al., 2004).

Verificou-se que a inibição do crescimento micelial, dos fungos fitopatogênicos estudados, foi maior quando o EBA foi obtido de plantas coletas no outono, seguida das coletadas no verão. CARneiro; Fernandes (1996) citam que em ambientes adversos (temperaturas mais elevadas, baixa precipitação pluviométrica entre outros), as plantas utilizam sua energia e seus recursos na produção de metabólitos secundários (compostos químicos) para se defenderem de insetos herbívoros, micro-organismos patogênicos e outros inimigos naturais.

LAVABre (1997) e MARTins et al. (2000) citaram que o papel dos óleos essenciais é o de ajudar a planta a se adaptar ao meio ambiente, por isso sua produção aumenta em situações de estresse. Considerando que óleos essenciais são substâncias de defesa da plantas sintetizados em condições de cultivo adversas, como temperaturas elevadas ou períodos longos de estiagem, aliado ao fato da espécie em questão ser oriunda da Ásia, portanto, espécie exótica ou introduzida, nos leva a crer que, provavelmente, as plantas colhidas no outono e no verão possuam maior teor de óleo essencial. Isto pode ser explicado pelo fato dessas encontrarem nestas estações condições de estresse hídrico e temperaturas elevadas, respectivamente, ocasionando maiores teores de óleo essencial nestas épocas do ano. Já no inverno a taxa de crescimento das plantas reduz muito e com isto, provavelmente, a produção dos metabólitos secundários.
Castro; Chemale (1995) recomendam que a colheita da espécie Ocimum basilicum, planta do mesmo gênero, deva ser realizada no outono, quando o interesse for produção de folhas e no verão, quando o interesse for produção de flores, o que corrobora com o maior efeito antifúngico obtido neste trabalho, quando as plantas foram coletadas justamente nestas estações do ano. Assim, os extratos brutos aquosos, mesmo na menor concentração testada (5\%), ocasionaram inibição do crescimento micelial dos fitopatógenos.

\section{CONCLUSÕES}

Os resultados obtidos neste trabalho indicam que tanto o extrato bruto aquoso como o óleo essencial de $O$. gratissimum apresenta-se promissor para o controle de fitopatógenos e que plantas colhidas no outono e verão apresentam maior teor de substâncias com características fungicidas.

\section{REFERÊNCIAS}

AWAH, R.T. Fungitoxic effects of extracts from some West African plants. Annals of Apllied Biology, v.115, n.3, p.451-453, 1989.

AWAH, R.T. In vivo use of extracts from Ocimum gratissimum and Cymbopogon citratus against Phythophthora palmivora causing blackpod disease of cocoa. Annals of Apllied Biology, v.124, n.1, p.173-178, 1994.

BALBI-PEÑA, M.I., BECKER, A.; STANGARLIN, J.R.; FRANZENER, G.; LOPES M.C.; SCHWANESTRADA, K.R.F. Controle de Alternaria solani em tomateiro por extratos de Curcuma longa e curcumina - I. Avaliação in vitro. Fitopatologia Brasileira, v.31, n.3, p.310-314, 2006.

BASTOS, C.N. Efeito do óleo de Piper aduncum sobre Crinipellis perniciosa e outros fungos fitopatogênicos. Fitopatologia Brasileira, v.22, n.3, p.441-443, 1997.

CARNEIRO, M.A.A.; FERNANDES, G.W. Sexo, drogas e herbivoria. As relações conflituosas entre plantas e insetos. Ciência Hoje, v.20, n.118, p. 32-35, 1996.

CARVALHO FILHO, J.L.S.; ALVES, P.B.; EHLERT, P.A.D.; MELO, A.C.; CACALCANTI, S.C.H.; ARRIGONI-BLANK, M.F.; SILVA-MANN, R; BLANK, A.F. Influence of the harvesting time, temperature and drying period on basil (Ocimum basilicum) essential oil. Revista Brasileira de Farmacognosia, v.16, n.1, p.24-30, 2006.

CASTRO, H.G.; FERREIRA, F.A. Contribuição ao estudo das plantas medicinais: carqueja (Baccharis genistelloides). Viçosa, MG: UFV, 2000. 10p. 
CASTRO, L.O.; CHEMALE, V.M. Plantas medicinais, condimentares e aromáticas. Guaíba: Agropecuária, 1995. $196 \mathrm{p}$.

CASTRO, H.G.; FERREIRA, F.A.; SILVA, D.J.H.; MOSQUIM, P.R. Contribuição ao estudo das plantas medicinaismetabólitos secundários. 2.ed. Visconde de Rio Branco, 2004. 113p.

COSTA, A. F. Farmacognosia. Lisboa: Fundação Calouste Gulbenkian, 1986. v.1. 1031p.

DUBEY, K.N.; TIWARI, T.N.; MANDIN, D.; ANDRIAMBOAVONJY, H.; CHAUMONT, J.P. Antifungal properties of Ocimum gratissimum essential oil (ethyl cinnamate chemotype). Fitoterapia, v.71, n.5, p.567-569, 2000.

FARIA, T.J.; FERREIRA, R.S.; YASSUMOTO, L.; SOUZA, J.R.P.; ISHIKAWA, N.K.; BARBOSA, A.M. Antifungal of essential oil isolated from Ocimum gratissimum L. (eugenol chemotype) against phytopathogenic fungi. Brazilian Archives of Biology and Technology, v.49, n.6, p.867-871, 2006.

FENG, W.; ZHENG, X. Essential oils to control Alternaria alternata in vitro and in vivo. Food Control, v.18, n.9, p.1126-1130, 2007.

FIORI, A.C.G.; SCHWAN-ESTRADA.; STANGARLIN, J.R.; VIDA, J.B.; SCAPIM, C.A.; CRUZ, M.E.S.; PASCHOLATI, S.F. Antifungal activity of leaf extracts and essencial oils of some medicinal plants against Didymella bryoniae. Journal of Phytopathology, v.148, n.7/8, p.483, 2000.

LAVABRE, M. Aromaterapia: a cura pelos óleos essenciais. Rio de Janeiro: Record, 1997. 172p.

MARTINS, E.R.; CASTRO, D.M.; CASTELLANI, D.C.; DIAS, J.E. Plantas Medicinais. Viçosa: Editora UFV, 2000. $220 \mathrm{p}$.
MATOS, F.J. A. As plantas da farmácia viva. Fortaleza: BNB, 1997. 57p.

NAKAMURA, C.V.; ISHIDA, K.; FACCIN, L.C.; DIAS FILHO, B.P; CORTEZ, D.A.G.; ROZENTAL, S.; SOUZA, W.; UEDA-NAKAMURA, T. In vitro activity of essential oil from Ocimum gratissimum L. against four Candida species. Research in Microbiology, v.155, n.7, p.579-586, 2004.

ROSSET, M.; ZAMARION, V.M.; FACCIONE, M.; FARIA T.J.; PINTO J.P.; BARBOSA, A.M.; SOUZA, J.R.P. Estudo químico da fração diclorometânica do extrato de Ocimum gratissimum L. Semina: Ciências Agrárias, v.26, n.4, p.515-520, 2005.

ROZWALKA, L.C. Controle alternativo da antracnose em frutos de goiabeira, em laboratório. 2003. 45p. Dissertação (Mestrado)-Universidade Federal do Paraná, Curitiba, PR, 2003.

SAS INSTITUTE ser's guide: statistics, version 9.1. Cary: SAS Institute, 2002.

SILVA, I.; MIRANDA NETO, M.H.; FRANCO, S.L.; CARDOSO, M.L.C.; MOLINARI, S.L.; SANT'ANA, D.M.G.; CONEGERO, C.I.; IWANKO, N.S. Noções sobre o organismo humano e utilização de plantas medicinais. Cascavel: Assoeste, 1995. 203p.

STANGARLIN, J.R.; SCHWAN-ESTRADA, K.R.F.; CRUZ, M.E.S.; NOZAKI, M.H. Plantas medicinais e controle alternativo de fitopatógenos. Biotecnologia, Ciência \& Desenvolvimento, n.11, p.16-21, 1999.

VIEIRA, R.F.; SIMON, F.E. Chemical characterization of basil (Ocimum spp.) found in the markets and used in traditional medicine in Brazil. Economic Botany, v.54, n.2, p.207-216, 2000.

Recebido em 30/6/09

Aceito em 10/8/10 